\title{
Pengaruh Social Media Marketing Dan Trust Terhadap Minat Menggunakan Gopay Di Jakarta
}

\author{
Christian Ponarwan dan Miharni Tjokrosaputro \\ Program Studi Manajemen/Akuntansi, Fakultas Ekonomi dan Bisnis \\ Universitas Tarumanagara, Jakarta \\ Email: ponarwanchristian@yahoo.co.id; miharnit@fe.untar.ac.id
}

\begin{abstract}
The purpose of this study is to empirically test whether social media marketing and consumer confidence have an influence on the interest in using Gopay in Jakarta. This research method is quantitative research, with cross sectional research design. The subjects in this study were active Gopay users who used Gopay in the last 1-3 months. Respondents collected in this study were 255 and only 244 were valid. The sample selection technique uses the convenience sampling method. This research instrument uses a questionnaire that was polled through Google Form. Each questionnaire statement contains indicator items consisting of social media marketing (8 items), consumer confidence (5 items), and buying interest (5 items). Statements are measured using the Likert Scale 1-4 where 1 (strongly disagree) and 4 (strongly agree).The results showed that there was a positive and significant influence in the relationship between social media marketing (X1) and consumer confidence (X2) on the interest in using Gopay (Y). Based on these results, it is hoped that Gopay will continue to develop marketing activities through social media and continue to maintain consumer trust.
\end{abstract}

Keywords: social media marketing, consumer trust, purchase intention,

Abstrak: Tujuan dari penelitian ini adalah untuk menguji secara empiris apakah pemasaran media sosial dan kepercayaan konsumen memiliki pengaruh terhadap minat menggunakan Gopay di Jakarta. Metode penelitian ini adalah penelitian kuantitatif, dengan desain penelitian cross sectional. Subjek dalam penelitian ini adalah pengguna Gopay aktif yang menggunakan Gopay dalam 1-3 bulan terakhir. Responden yang dikumpulkan dalam penelitian ini adalah 255 dan hanya 244 yang valid. Teknik pemilihan sampel menggunakan metode convenience sampling. Instrumen penelitian ini menggunakan kuesioner yang disurvei melalui Formulir Google. Setiap pernyataan kuesioner berisi item indikator yang terdiri dari pemasaran media sosial (8 item), kepercayaan konsumen (5 item), dan minat beli (5 item). Pernyataan diukur menggunakan Skala Likert 1-4 di mana 1 (sangat tidak setuju) dan 4 (sangat setuju). Hasil menunjukkan bahwa ada pengaruh positif dan signifikan dalam hubungan antara pemasaran media sosial (X1) dan kepercayaan konsumen (X2) tentang minat menggunakan Gopay (Y). Berdasarkan hasil ini, diharapkan bahwa Gopay akan terus mengembangkan kegiatan pemasaran melalui media sosial dan terus mempertahankan kepercayaan konsumen.

Kata Kunci: social media marketing, kepercayaan konsumen, minat beli

\section{LATAR BELAKANG}

Pada zaman milenial ini, peningkatan dalam penggunaan teknologi digital, komunikasi, dan media sosial dapat sangat dirasakan. Berbagai macam kemudahan dan efisiensi 
ditawarkan bagi mereka yang mampu menggunakan berbagai macam kemajuan teknologi digital dan media yang ada. Salah satu kemudahan yang dapat dirasakan yakni dalam hal transaksi jual beli barang dan jasa. Menurut data Google dan Temasek pada tahun 2017, dikutip dari www.liputan6.com/tekno (27/2/18), pembelian produk via e-Commerce di Indonesia mencapai US\$10,9 miliar atau sekitar Rp 146,7 triliun, meningkat 41 persen dari angka US\$ 5,5 miliar atau sekitar Rp 74 triliun pada tahun 2015. Fasilitas lain yang disediakan oleh aplikasi jual beli barang dan jasa yaitu metode pembayaran dengan menggunakan e-money atau e-payment. Menurut Tan (2004), definisi e-payment adalah dimana nilai moneter ditransfer secara elektronik atau digital antara dua entitas sebagai kompensasi atau pertimbangan untuk penerimaan barang atau jasa.

Salah satu perusahaan yang menjalankan bisnis e-payment ini adalah perusahaan Gojek yakni sistem pembayaran dengan aplikasi Gopay. Konsumen bisa menggunakan layanan Gopay untuk membayarkan pesanannya di aplikasi Gojek sehingga tidak perlu menggunakan uang cash untuk melakukan transaksi. Penggunaan Gopay di Indonesia sebagai sistem pembayaran pengganti uang tunai sudah memiliki peminat yang cukup besar. Menurut MDI Ventures dan Mandiri Sekuritas dalam situs https://dailysocial.id (6/3/18), menyatakan bahwa Gopay dan OVO menjadi dompet elektronik yang paling bersaing dengan pengguna terbanyak di Indonesia

Setiap perusahaan yang melalukan sebuah bisnis pasti memiiki orientasi untuk mendapatkan keuntungan. Keuntungan dapat dihasilkan apabila masyarakat memiliki minat untuk membeli produk yang ditawarkan oleh perusahaan tersebut, lalu baru kemudian melakukan pemelian aktual. Social media marketing merupakan salah satu faktor yang dapat mempengaruhi minat beli (Laksamana, 2018; Kim \& Ko, 2012). Kim \& Ko (2012) menungkapkan social media marketing memberi pengaruh positif dan signifikan terhadap minat beli. Social media marketing berkontribusi sebagai metode komunikasi pemasaran yang efektif. Penguna social media yang begitu besar dapat dimanfaatkan oleh Gopay sebagai sarana untuk memasarkan produk layanannya terhadap konsumen.

Kepercayaan konsumen juga menjadi faktor lain yang dapat mempengaruhi minat beli (Ling, Chai, \& Phiew, 2011). Hasil penelitian Ling, Chai, \& Phiew (2011) menunjukan bahwa kepercayaan konsumen berpengaruh positif dan signifikan terhadap minat beli. Berdasarkan hasil perhitungan dalam penelitian tersebut, kepercayaan konsumen memiliki $\mathrm{p}$ value sebesar 0,000 lebih rendah dari alpha value sebesar 0,005. Hal ini dapat menjadi perhatian bagi Gopay untuk meningkatkan rasa percaya masyarakat untuk menggunakan Gopay.

\section{KAJIAN TEORI}

Teori yang digunakan dalam penelitian ini adalah The Theory of Reason Action (Fishbein dan Ajzen,1980). Teori ini menjelaskan bahwa niat dipengaruhi oleh sikap dan norma berdasarkan situasi, perilaku, dan perbedaan indvidu. Lee dan Kotler (2011) mengatakan niat ini ditentukan oleh dua faktor utama: keyakinan kita tentang hasil yang terkait dengan perilaku dan persepsi kita tentang bagaimana orang lain akan melihat perilaku tersebut Kepercayaan konsumen dan social media marketing dapat memberikan informasi yang menimbulkan pandangan calon pembeli terhadap produk tersebut. Informasi yang dapat diterima seperti keunggulan produk, review dari pengguna lain mengenai produk tersebut, dan sebagainya. Ketika konsumen mendapatkan informasi bahwa produk tersebut dapat dipercaya, makan akan timbul niat membeli kepada produk tersebut. Sebaliknya, jika 
informasi yang didapatkan mengenai penjual adalah informasi yang buruk, maka hal tersebut akan mempengaruhi perilaku konsumen dan niat veli dari konsumen tersebut.

Social Media Marketing. Dwivedi, Kapoor, \& Chen (2015) mengatakan bahwa social media marketing dapat menjadi saranan komunikasi terbuka tentang beberapa informasi dan promosi sehingga memungkinkan pembelajaran dari antar pengguna produk tersebut. Tuten \& Solomon (2015) mengatakan social media marketing adalah pemanfaatan teknologi media sosial dan perangkat lunak untuk bertukar penawaran antara penjual dan pembeli yang memiliki nilai bagi pemangku kepentingan organisasi. Peters (2011) mengatakan social media marketing memanfaatkan situs jejaring sosial, blog, artikel, dan publikasi secara online untuk mempublikasikan dan mengkampanyekan produknya agar konsumen bisa mengetahui keberadaan dari produk tersebut. Melalui definisi diatas, dapat disimpulkan bahwa social media marketing adalah suatu pemanfaatan dari teknologi sosial berbentuk media, yang digunakan untuk mengkomunikasikan, menyampaikan, dan melakukan penawaran mengenai nilai dari suatu organisasi terhadap konsumen

Kepercayaan Konsumen. Menurut Jones \& Leonard (2012), kepercayaan konsumen dikatakan sebagai suatu hal yang sangat penting dalam penggunaan transaksi online karena membantu konsumen dalam menghadapi persepsi ketidakpastian dan resiko. Firmansyah (2018) mengatakan kepercayaan konsumen adalah pengetahuan konsumen terhadap suatu objek, atribut, dan manfaatnya di mana kepercayaan bersama sikap dan perilaku berkaitan dengan atribut produk. Ketika penipuan atau pengalaman pembelian negatif terjadi, pembeli menghasilkan sikap negatif, mereka tidak lagi mempercayai penjual, dan mereka cenderung beralih ke alternatif untuk pemenuhan kebutuhan dan keinginan mereka (Lee, 2014).

Minat Beli. Shah et al., (2012) mengatakan minat beli sebagai sebuah tindakan yang diteliti untuk mengetahui mengapa seorang konsumen mau membeli sebuah merek produk. Halakrispen (2015) mengungkapkan minat beli merupakan sesuatu yang berhubungan dengan rencana konsumen untuk membeli produk serta banyaknya unit produk yang dibutuhkan pada periode tertentu. Hal serupa juga dikemukakan oleh Younus, Rasheed, dan Zia (2015) yang mengatakan bawa minat beli adalah pilihan dari konsumen untuk membeli produk atau layanan. 


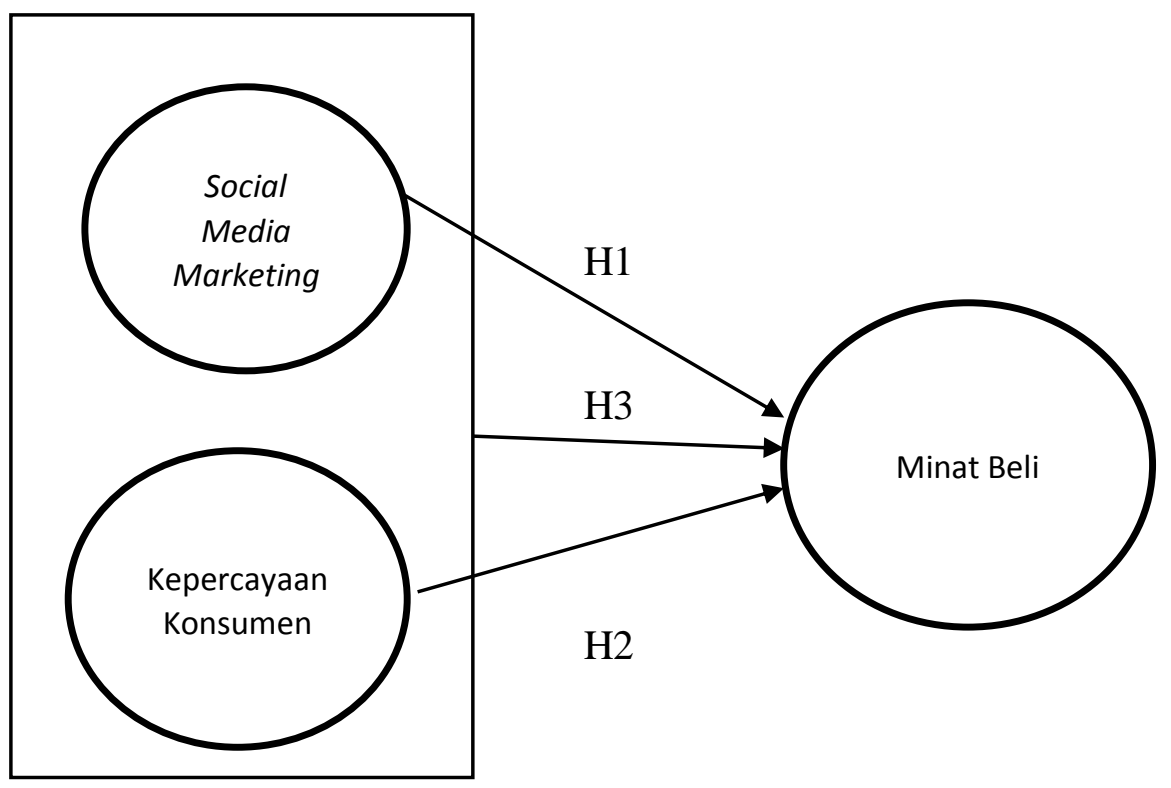

Gambar 1. Kerangka Pemikiran

H1: Social media marketing berpengaruh positif dan signifikan terhadap minat menggunakan Gopay di Jakarta

H2: Kepercayaan konsumen berpengaruh positif dan signifikan terhadap minat menggunakan Gopay di Jakarta

H3: Social media marketing dan kepercayaan konsumen secara bersama berpengaruh positif dan signifikan terhadap minat menggunakan Gopay di Jakarta

Kaitan Antar Variabel. Kim \& Ko (2012) menungkapkan social media marketing memberi pengaruh positif dan signifikan terhadap minat beli. Social media marketing berkontribusi sebagai metode komunikasi pemasaran yang efektif. Dengan meningkatnya minat terhadap merek-merek fashion mewah dalam memberikan nilai-nilai mewah kepada pelanggan dengan segala cara yang memungkinkan, menggunakan media sosial untuk pemasaran tampaknya menjadi media yang tepat untuk menarik minat beli konsumen mewah saat ini.

Berdasarkan hasil penelitian oleh Sevim dan Hall (2014), ditemukan hasil yang menunjukan bahwa kepercayaan konsumen memberikan pengaruh yang signifikan terhadap minat beli. Hasil tersebut diperoleh melalui perhitungan statistic analisis regresi $(F=71,49$, $\mathrm{p}<0,01)$. Kepercayaan konsumen dalam peneleitian ini memiliki bobot $37 \%$ dari seluruh variabel dependen yang mempengaruhi minat beli

Anwar dan Aprilia (2018) dalam penelitiannya juga menemukan hasil dimana social media marketing dan kepercayaan konsumen secara bersama berpengaruh positif terhadap minat beli. Berdasarkan uji ANOVA atau F test, diperoleh $F$ hitung sebesar 33,82 dengan tingkat signifikansi 0,000. Dengan demikian, terbukti bahwa kepercayaan dan media sosial berpengaruh secara simultan terhadap keputusan pembelian. 


\section{METODOLOGI}

Penelitian ini menggunakan metode penelitian deskriptif kuantitatif. Metode lain yang digunakan dalam penelitian ini adalah metode kuantitatif. Secara lebih terperinci, peneliti menggunakan desain penelitian Cross Sectional. Menurut Kesmodel (2018), studi crosssectional ditandai oleh pengumpulan informasi (data) yang relevan secara sekaligus pada kondisi titik waktu tertentu.

Populasi dalam penelitian ini adalah pengguna aktif Gopay di Jakarta. Teknik pemilihan sampel yang digunakan oleh peneliti adalah Non-Probability Sampling yang lebih tepatnya Convenience Sampling. Convenience sampling menurut Etikan dan Bala (2016) adalah adalah jenis non probability atau non random sampling di mana target anggota populasi adalah yang memenuhi kriteria praktis tertentu, seperti aksesibilitas mudah, kedekatan geografis, ketersediaan pada waktu tertentu, atau kesediaan untuk berpartisipasi untuk tujuan penelitian. Jumlah sampel yag ada adalah sebanyak 255 responden, Setelah melalui proses sorting, hanya terdapat 244 jawaban responden yang digunakan sebagai data dalam penelitian ini.

Instrumen yang digunakan peneliti dalam penelitian ini adalah kuesioner/angket. Pertanyaan-pertanyaan dalam kuesioner/angket tersebut kemudiaan diukur dengan menggunakan Likert. Skala dalam setiap pernyataan/pertanyaan dalam penelitian ini dibagi menjadi 4 (empat) yaitu 1 adalah sangat tidak setuju, 2 adalah tidak setuju, 3 adalah setuju, dan 4 adalah sangat setuju. Setiap variabel diwakili oleh beberapa instrumen/indikator pernyataan yang diajukan kepada responden. Variabel social media marketing terdiri dari delapan indikator, kepercayaan konsumen terdiri dari lima indikator, dan minat beli terdiri dari lima indikator.

Analisis data dalam penelitian ini menggunakan regresi linear berganda (multiple regression analysis). Uji hipotesis dilakukan melalui tiga tahap, yaitu uji t/uji parsial, uji F/uji stimulan, dan uji $\mathrm{R}^{2}$. Pengujian hipotesis dilakukan dengan menggunakan program SPSS 25. Pada penelitian ini, untuk menganalisis data digunakan uji asumsi klasik yang dibagi menjadi tiga bagian, yaitu uji normalitas, uji heterokedastisitas, dan uji multikolinearitas.

\section{HASIL ANALISIS DATA}

Subjek yang ada dalam penelitian ini adalah pengguna aktif Gopay yang berdomisili di Jakarta. Subjek yang dapat digunakan dalam penelitian ini harus memenuhi kriteria, yaitu merupakan pengguna aktif Gopay dan pemakaian aplikasi Gopay dilakukan maksimal 1-3 bulan terakhir. Berdasarkan hasil perhitungan, ditemukan bahwa dari 244 responden pengguna Gopay di Jakarta, diperoleh data yang menunjukan bahwa mayoritas responden adalah perempuan sebanyak 140 responden $(57.4 \%)$ dan sisanya adalah laki laki sebanyak 104 responden (42.6\%). Hasil perhitungan subjek penelitian berdasarkan usia didominasi oleh responden dengan rentan usia 21-25 tahun sebanyak 205 responden (84\%). Pada posisi kedua, ditempati oleh responden dengan rentan usia 18-20 tahun sebanyak 24 responden (9.8\%) kemudian diikuti oleh responden dengan rentan usia 26-30 tahun sebanyak 11 responden (4.5\%). Responden dengan rentan usia 31-35 tahun dan lebih dari (>) 35 tahun memiliki jumlah yang paling sedikit, yaitu masing-masing sebanyak 2 responden $(0.8 \%)$. 
Analisis Validitas dan Reabilitas. Setiap indikator pernyataan dari variabel social media marketing, kepercayaan konsumen, dan minat beli telah diuji terhadap 244 responden. Berdasarkan hasil penelitian, seluruh indikator memiliki nilai corrected item-total colleration lebih dari 0.3, dengan demikian seluruh indikator dinyatakan valid (Sugiyono, 2013:124). Hasil pengujian validitas ditunjukan pada (Tabel 1, Tabel 2, dan Tabel 3.

Tabel 1. Uji Validitas Social Media Marketing

\begin{tabular}{|c|c|c|}
\hline Pernyataan & Corrected Item-Total Colleration & Hasil \\
\hline Social Media Marketing 1 & 0.703 & Valid \\
\hline Social Media Marketing 2 & 0.692 & Valid \\
\hline Social Media Marketing 3 & 0.662 & Valid \\
\hline Social Media Marketing 4 & 0.605 & Valid \\
\hline Social Media Marketing 5 & 0.632 & Valid \\
\hline Social Media Marketing 6 & 0.593 & Valid \\
\hline Social Media Marketing 7 & 0.666 & Valid \\
\hline Social Media Marketing 8 & 0.647 & Valid \\
\hline
\end{tabular}

Tabel 2. Uji Validitas Kepercayaan Konsumen

\begin{tabular}{|c|c|c|}
\hline Pernyataan & Corrected Item-Total Colleration & Hasil \\
\hline Kepercayaan Konsumen 1 & 0.598 & Valid \\
\hline Kepercayaan Konsumen 2 & 0.663 & Valid \\
\hline Kepercayaan Konsumen 3 & 0.714 & Valid \\
\hline Kepercayaan Konsumen 4 & 0.683 & Valid \\
\hline Kepercayaan Konsumen 5 & 0.700 & Valid \\
\hline
\end{tabular}

Tabel 3. Uji Validitas Minat Beli

\begin{tabular}{|c|c|c|}
\hline Pernyataan & Corrected Item-Total Colleration & Hasil \\
\hline Minat Beli 1 & 0.566 & Valid \\
\hline Minat Beli 2 & 0.541 & Valid \\
\hline Minat Beli 3 & 0.562 & Valid \\
\hline Minat Beli 4 & 0.608 & Valid \\
\hline Minat Beli 5 & 0.464 & Valid \\
\hline
\end{tabular}

Pengukuran reabilitas dilakukan dengan menggunakan Alpha Cronbach. Menurut Ghozali (2018), nilai keandalan yang dapat diterima atau dikatakan reliabel apabila memiliki nilai Alpha Cronbach yaitu sebesar 0,7 atau lebih tinggi. Seluruh variabel dinyatakan bersifat reliabel. Program komputer yang digunakan untuk menanalisis reliabilitas data yaitu SPSS 25. Hasil pengujian validitas ditunjukan pada Tabel 
Tabel 4. Uji Reliabilitas Social Media Marketing, Kepercayaan Konsumen, Minat Beli

\begin{tabular}{|c|c|}
\hline Variabel & Alpha Cronbach \\
\hline Social media Marketing & 0.882 \\
\hline Kepercayaan Konsumen & 0.856 \\
\hline Minat Beli & 0.770 \\
\hline
\end{tabular}

\section{HASIL UJI ASUMSI KLASIK}

Normalitas. Pengujian normalitas dalam penelitian ini menggunakan uji normalitas Kolmogorov-Smirnov dengan menerapkan nilai signifikansi sebesar $>0.05$, dimana apabila nilai signifikansi yang dihasilan berada diatas nilai 0.05 , maka hal tersebut menunjukan bahwa data terdistribusi secara normal (Ghozali, 2013). Berdasarkan Tabel 5, dapat diketahui bawa dari 244 responden yang ada, dapat terkumpul data dengan nilai signifikansi sebesar 0.094 , di mana hal tersebut menyatakan bahwa regresi terdistribusi secara normal $(>0.05)$

Tabel 5. Hasil Uji Normalitas Kolmogorov-Smirnov

\begin{tabular}{|c|c|}
\hline N & Asymp. Sig. (2-tailed) \\
\hline 244 & 0.094 \\
\hline
\end{tabular}

Heterokedastisitas. Menurut Ghozali (2013), uji heteroskedastisitas berfungsi untuk melakukan pengujian terhadap model regresi untuk mengetahu apakah terjadi ketidaksamaan varian dari residual antar pengamatan. Peneliti menggunakan uji koefisien kolarasi Spearman untuk menguji terjadi atau tidaknya heterokedastisitas (Purnomo, 2017). Menurut Purnomo (2017) apabila nilai signifikansi lebih dari 0.05, maka dapat dinyatakan tidak terjadi heterokedastisitas. Nilai signifikansi dari variabel social media marketing dan kepercayaan konsumen berada di angka 0.202 dan 0.513 , sehingga dpaat dinyatakan tidak terjadi heterokedastisitas.

Tabel 6. Hasil Uji Heterokedastisitas (Uji Spearman)

\begin{tabular}{|c|c|}
\hline Variabel & Sig. (2-tailed) \\
\hline Social Media Marketing & 0.202 \\
\hline Kepercayaan Konsumen & 0.513 \\
\hline
\end{tabular}

Multikolinearitas, Analisis Regresi Ganda, dan Uji t. Pengujian multikolonieritas memiliki maksud untuk menguji apakah di dalam model regresi didapati adanya kolerasi atau hubungan antara masing-masing variabel independen (Ghozali, 2018). Peneliti menggunakan batas nilai toleransi $<0,10$ atau sama dengan nilai VIF $>10$ (Ghozali, 2018) untuk menunjukan adanya indikasi multikolinearitas dalam penelitian ini. Berdasarkan 
Tabel 7, peneliti menyimpulkan bahwa nilai tolerance untuk variabel independen social media marketing dan kepercayaan konsumen yaitu sebesar 0.735 serta nilai Variance Inflation Factor (VIF) sebesar 1.361, dimana hal tersebut berarti tidak terdapat indikasi multikolinearitas dalam kedua variabel tersebut.

Berdasarkan Montgomery dkk. (2012), persamaan regresi yang digunakan pada penelitian ini dirumuskan menjadi ( $\mathrm{Y}=\mathrm{a}+\mathrm{b} 1 \mathrm{X} 1+\mathrm{b} 2 \mathrm{X} 2)$. Pada persamaan tersebut, akan dilakukan pengujian terhadap pengaruh social media marketing dan kepercayaan konsumen terhadap minat beli. Berdasarkan Tabel 8, dapat diketahui bahwa nilai signifikansi dari variabel social media marketing berada pada angka 0.000, dimana nilai tersebut lebih kecil dari $\alpha=0.05$. Melalui hal tersebut, dapat disimpulkan bahwa social media marketing sebagai variabel independen memberikan pengaruh yang signifikan terhadap minat beli sebagai variabel dependen. Berdasarkan Tabel 8, dapat diketahui juga bahwa nilai signifikansi dari variabel kepercayaan konsumen berada pada angka 0.000, dimana nilai tersebut lebih kecil dari $\alpha=0.05$. Melalui hal tersebut, dapat disimpulkan bahwa kepercayaan konsumen sebagai variabel independen memberikan pengaruh yang signifikan terhadap minat beli sebagai variabel dependen.

Tabel 7. Hasil Uji Multikolinearitas

\begin{tabular}{|l|c|c|}
\hline \multicolumn{1}{|c|}{ Variabel Independen } & Tolerance & $\begin{array}{c}\text { Variance Inflation Factor } \\
\text { (VIF) }\end{array}$ \\
\hline Social Media Marketing & 0.735 & 1.361 \\
\hline Kepercayaan Konsumen & 0.735 & 1.361 \\
\hline
\end{tabular}

Tabel 8. Hasil Uji t

\begin{tabular}{|l|c|c|}
\hline \multicolumn{1}{|c|}{ Model } & t & sig \\
\hline Constant & 3.731 & 0.000 \\
\hline Social Media Marketing & 7.546 & 0.000 \\
\hline Kepercayaan Konsumen & 8.032 & 0.000 \\
\hline
\end{tabular}

Uji F. Berdasarkan kutipan dari Suyono (2018), uji F dalam penelitian ini dilakukan dengan membandingkan nilai probabiliotas (Sig.) dengan $\alpha$, dimana $\alpha=0.05$. Apabila nilai (Sig.) lebih kecil dari $\alpha$, maka terdapat variabel independent secara simultan/bersama berpengaruh terhadap variabel dependen. Berdasarkan Tabel 9, diketahui bahwa nilai signifikansi dari hasil uji $\mathrm{F}$ berada pada angka 0.000. Nilai signifikansi yang ada pada uji $\mathrm{F}$ dalam penelitian ini menunjukan hasil yang lebih kecil dari $\alpha=0.05$. Berdasarkan hal tersebut, peneliti dapat 
menyimpulkan bahwa social media marketing dan kepercayaan konsumen secara bersama memiliki pengaruh yang signifikan terhadap minat beli

Tabel 9. Hasil Uji F

\begin{tabular}{|c|c|c|}
\hline Model & F & Sig. \\
\hline Regression & 125.132 & $0.000^{\mathrm{b}}$ \\
\hline
\end{tabular}

Uji $\mathbf{R}^{2 \cdot}$ Uji R Square dilakukan untuk mengetahui seberapa besar kemampuan variabel independent dalam memberikan pengaruh terhadap variabel dependen (Ghozali, 2018). nilai adjusted R square adalah sebesar 0.594. Melalui hasil tersebut, dapat di interpretasikan bahwa variabel independen (social media marketing dan kepercayaan konsumen) dapat menjelaskan atau memberikan kontribusi terhadap variabel dependen (minat beli) sebesar $50.5 \%$.

Tabel 10. Hasil Uji $\mathrm{R}^{2}$

\begin{tabular}{|c|c|}
\hline Model & Adjusted $R$ square \\
\hline 1 & 0.505 \\
\hline
\end{tabular}

\section{DISKUSI}

Hasil analisis data melalui uji t menunjukan bahwa social media marketing berpengaruh positif dan signifikan terhadap minat menggunakan Gopay di Jakarta (Hipotesis 1 terbukti). Kemajuan pesat teknologi internet membuat angka pengguna media sosial terutama di Indonesia mengalami kenaikan tiap tahunnya. Naiknya pengguna media sosial ini juga mempengaruhi kegiatan jual beli yang dilakukan secara online. Pemanfaatan media sosial untuk memasarkan produk baik barang maupun jasa menjadi pilihan utama saat ini, mengingat penguna media sosial yang begitu banyak dan jangkauan yang bisa diperoleh melalui media sosial sangat luas. Masyarakat yang sudah jarang menggunakan media lain seperti media cetak dan tv karena sudah beralih ke social media membuat proses pemasaran melalui social media memberikan pengaruh yang signifikan terhadap minat beli konsumen.

Hasil analisis data melalui uji t menunjukan bahwa kepercayaan konsumen berpengaruh positif dan signifikan terhadap minat menggunakan Gopay di Jakarta (Hipotesis 2 terbukti). Gopay sebagai salah satu metode/alat pembayaran yang bisa dikatakan baru bagi masyarakat harus mampu meyakinkan calon konsumennya bahwa Gopay akan memberikan pelayanan sesuai dengan harapan dari konsumen tersebut. Agar dapat meningkatkan minat konsumen untuk menggunakan produk layanannya, Gopay harus dapat merubah pola pikir masyarakat yang sudah lama terbiasa dengan sistem pembayaan yang lama untuk berganti haluan menjadi pengguna Gopay sebagai alat pembayaran. Bergantinnya haluan masyarakat sesuai dengan Theory Reason and Action adalah harus didasari dengan alasan yang kuat, salah satunya adalah alasan bahwa Gopay dapat dipercaya. Melalui alasan tersebut, selanjutnya konsumen akan melakukan action, yakni menjadi pengguna Gopay.

Hasil analisis data melalui uji $\mathrm{F}$ menunjukan bahwa social media marketing dan kepercayaan konsumen secara bersama berpengaruh positif dan signifikan terhadap minat 
menggunakan Gopay di Jakarta (Hipotesis 3 terbukti). Pengaruh dari social media marketing dan kepercayaan konsumen terhadap minat beli sebelumnya sudah diuji secara parsial dalam uji t. Hasilnya menunjukan bahwa kedua variabel tersebut berpengaruh positif dan signifikan. Apabila hasil dari uji $\mathrm{F}$ untuk menguji pengaruh secara simultan memiliki hasil yang positif dan signifikan, dapat disimpulkan bahwa hal tersebut wajar terjadi karena hasil yang ditunjukan pada uji parsial juga mengatakan hal yang sama. Ketika dua hal yang berpengaruh positif disatukan, maka pengaruh terhadap variabel dependen akan semakin besar

\section{PENUTUP}

Berdasarkan berbagai hasil analisis yang telah dijabarkan pada bab sebelumnya, dapat ditarik kesimpulan dari penelitian ini bahwa, pertama, kepercayaan konsumen memberikan pengaruh yang signifikan dan positif terhadap minat menggunakan Gopay di Jakarta. Kedua, social media marketing memberikan pengaruh yang signifikan dan positif terhadap minat menggunakan Gopay di Jakarta. Ketiga, social media marketing dan kepercayaan konsumen secara simultan berpengaruh signifikan dan positif terhadap minat menggunakan Gopay di Jakarta.

Berdasarkan kesimpulan yang telah ada, maka disajikan beberapa saran untuk berbagai pihak yaitu yang pertama, bagi Gopay, karena social media marketing secara signifikan mempengaruhi minat beli, maka kegiatan ini harus terus dilakukan agar semakin banyak masyarakat yang mengenal Gopay. Perkenalan akan produk Gopay di social media harus dibarengi dengan pemberian rasa percaya dari konsumen terhadap Gopay. Kedua, bagi masyarakat, hasil penelitian ini bisa menjadi acuan dalam memulai sebuah bisnis atau meningkatkan bisnis yang sudah ada. Pada era digital ini, sebagian besar masyarakat khususnya masyarakat Indonesia adalah pengguna internet dan media sosial. Ketiga, bagi akademisi, hasil perhitungan adjusted $R$ square menunjukan hasil sebesar 0.594 atau $59.4 \%$. Hal itu menunjukan bahwa masih ada sebesar $40.6 \%$ variabel lain yang mempengaruhi minat beli. Para akademisi bisa melakukan penelitian selanjutnya mengenai variabel lain yang dapat mempengaruhi minat beli sehingga semakin banyak pelaku usaha yang memiliki acuan untuk mengembangkan bisnisnya.

\section{DAFTAR PUSTAKA}

Ajzen, I., \&Fishbein, M. (1980). Understanding Attitudes and Predicting Social Behavior.Englewood Cliffs: Pretice-Hall

Dwivedi, Y.K., Kapoor, K.K., Chen, H. (2015). Social Media Marketing and Advertising. The Marketing Review, 15(3), 289-309

Etikan, Ilker dan Bala, Kabiru. (2017). Sampling and Sampling Methods. Biometrics \& Biostatistics International Journal, 5(6), 215-217

Firmansyah, M. Anang. (2018). Perilaku Konsumen: Sikap dan Pemasaran. Yogyakarta: Deepublish

Ghozali, Imam. (2013). Aplikasi Analisis Multivariate dengan Program SPSS: Edisi 7. Semarang: BPUNDIP

Ghozali, Imam. (2018). Aplikasi Analisis Multivariate dengan Program SPSS: Edisi 9. Semarang: BPUNDIP 
Halakrispen, Sunnaholomi. (2015). Pengaruh Fotografi Pemandangan Teluk Kilauan di Lampung dalam Situs www.dolphinkilauanbay.com Terhadap Minat Mahasiswa Universitas Surya untuk Mengunjungi Teluk Kilauan. Essence Jurnal Seni, Desain, Komunikasi, Peneliti Muda, 1, 31

Jones, K dan Leonanrd, L. N. K. (2012). Trust in consumer-to-consumer electronic commerce. Journal Information \& Management, 45, 88-95

Kesmodel, U. S. (2018). Cross-sectional studies - what are they good for. Acta Obstetricia et Gynecologica Scandinavica, 97(4), 388-393

Kim, A. J., \& Ko, E. (2012). Do Social Media Marketing Activities Enhance Customer Equity? An Empirical Study Of Luxury Fashion Brand. Journal of Business Research, 65(2012), 1480-1486

Laksamana, Patria. (2018). Impact of Social Media Marketing on Purchase Intention and Brand Loyalty: Evidence from Indonesia's Banking Industry. International Review Of Management and Marketing, 8(1), 13-18

Lee, N. R. dan Kotler, P. (2011). Social Marketing: Influencing Behaviors for Good. London: Sage Publication

Ling, K. C., Chai, L. T., \& Piew, T. H. (2011). The Effects of Shopping Orientations, Online Trust and Prior Online Purchase Experience toward Customers' Online Purchase Intention. International Business Research, 3(3), 63-76

Montgomery, D. C., Elizabeth P., dan Geoffrey V. (2012). Introduction To Linear Regression Analysis. New Jersey: Wiley

Peters, Audrey. (2011). Social Media Marketing For Small Business. Lulu.com

Purnomo, R. A. (2017). Analisis Statistik Ekonomi dan Bisnis Dengan SPSS. Ponorogo: WADE Group

Shah, H., Aziz, A., Jaffari, A. R., Waris, S., Ejaz, W., Fatima, M. and Sherazi., K. (2012). The Impact of Brands on Consumer Purchase Intentions. Asian Journal of Business Management, 4(2), 105-110

Sugiyono. (2013). Metode Penelitian Pendidikan Pendekatan Kuantitatif, Kualitatif, dan $R \& D$. Bandung: Alfabeta.

Suyono. (2018). Analisis Regresi Untuk Penelitian. Yogyakarta: Deepublish

Tan, Margaret. (2004). E-Payment: Digital Exchange. Lower Kent Ridge Road: NUS Publishing

Tuten, T. L., dan Solomon, M. R. (2015). Social Media Marketing. 2nd Edition. London: SAGE Publicatio

Younus, Sohail; Rasheed, F., dan Zia, A. (2015). Identifying the Factors Affecting Customer Purchase Intention. Global Journal of Management and Business Research: A Administration and Management, 15(2), 8-13. 